\title{
Equilibrium Solubility Investigation and Thermodynamic Computational Modeling of Halosulfuron-methyl in a Series of Cosolvent Mixtures at Temperature Range of (278.15-323.15) K
}

\author{
Guang Yang ${ }^{1}$, Jianqiang Zhang ${ }^{1}$, Chunjuan Huang ${ }^{2}$, Xin Song ${ }^{2}$, Renjie $\mathrm{Xu}^{*}, 2$ \\ ${ }^{1}$ Henan Provincial Key Laboratory of Surface \& Interface Science, Zhengzhou University of Light Industry, \\ Henan \\ 450001, People's Republic of China \\ ${ }^{2}$ Guangling College, Yangzhou University, Yangzhou, Jiangsu 225000, People's Republic of China \\ Corresponding author. Phone: + 86514 87993918; Fax: + 8651487994009 . \\ E-mail address: xurenjie126@163.com.
}




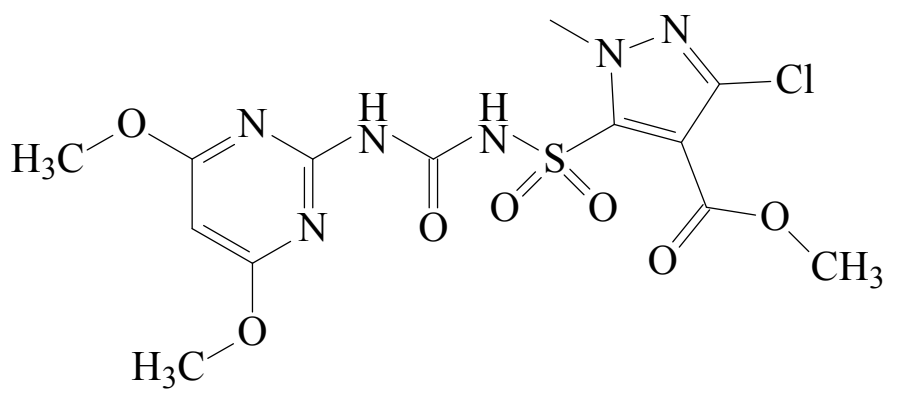

Fig. S1. Chemical structure of halosulfuron-methly. 


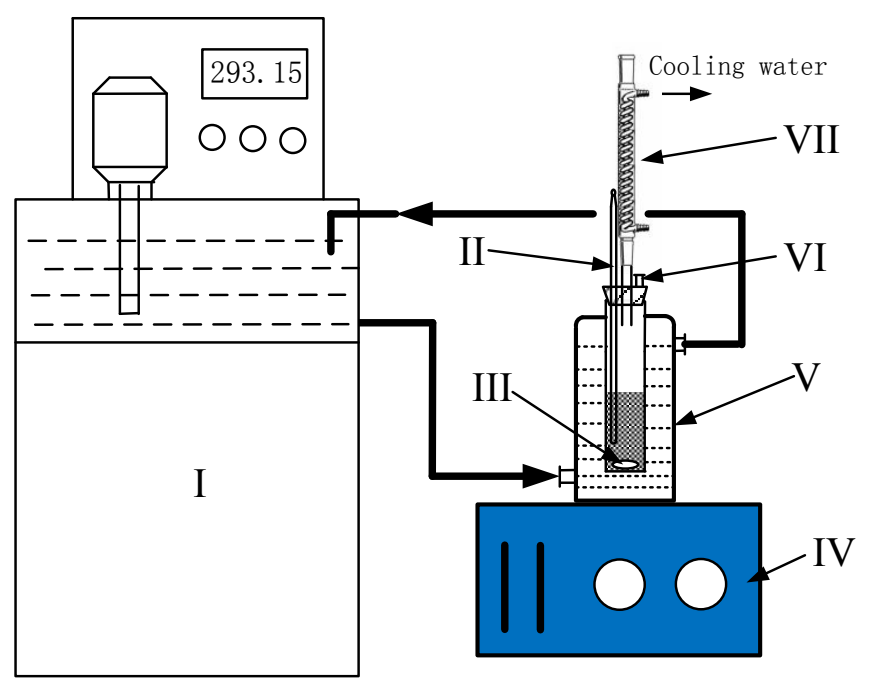

Fig. S2. Schematic diagram of experimental apparatus: I, smart thermostatic water bath; II, mercury-in-glass thermometer; III, magnetic stirrer; IV, stirrer controller; V, jacketed glass vessel; VI, sampling port; VII, condenser. 


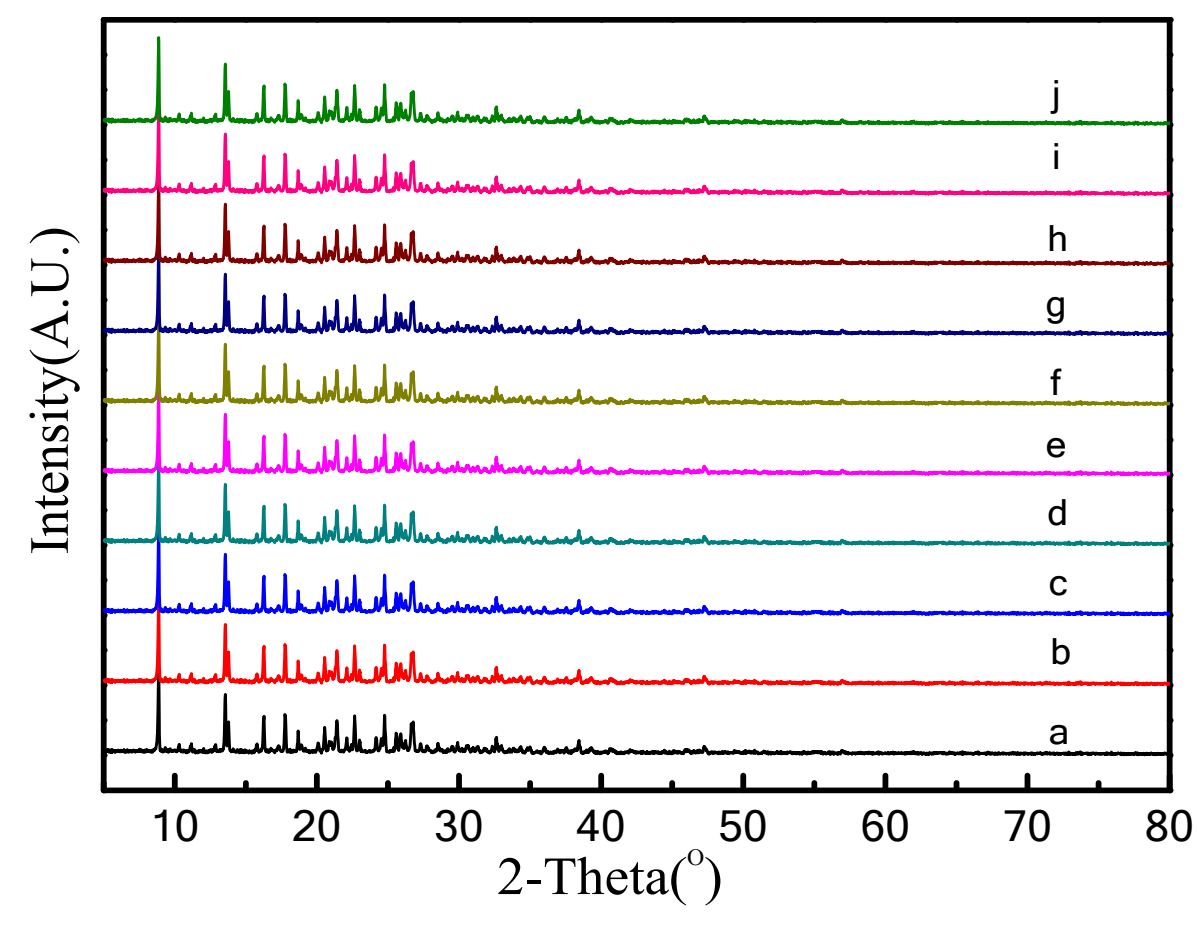

Fig. S3. XPRD patterns of halosulfuron-methly: (a) raw material; (b) crystallized in methanol; (c) crystallized in ethanol; (d) crystallized in isopropanol; (e) crystallized in DMF; (f) crystallized in water; (g) crystallized in methanol + water mixture; (h) crystallized in ethanol + water mixture; (i) crystallized in isopropanol + water mixture; (j) crystallized in DMF + water mixture. 